\title{
Microstructure and Dielectric Properties of Bi Substituted PLZMST Ceramics
}

\author{
Hayet Menasra, Zelikha Necira, Karima Bouneb, Abdelhak Maklid, Ahmed Boutarfaia* \\ Applied Chemistry Laboratory, Exact and Natural and Life Sciences Faculty, Materials Science Department, Mohamed Kheider Uni- \\ versity of Biskra, Biskra, Algeria. \\ Email: *hayetmenasra@yahoo.com
}

Received February $8^{\text {th }}, 2013$; revised April $4^{\text {th }}, 2013$; accepted April $17^{\text {th }}, 2013$

Copyright (C) 2013 Hayet Menasra et al. This is an open access article distributed under the Creative Commons Attribution License, which permits unrestricted use, distribution, and reproduction in any medium, provided the original work is properly cited.

\begin{abstract}
Bismuth (Bi) and lanthanum (La) doped lead manganese antimoine zirconate titanate (PZMST) ceramic powders have been synthesized by high temperature solid-state reaction method. Preliminary X-ray structural analysis of the compounds shows the formation of tetragonal structure. Scanning electron micrographs (SEM) shows a uniform grain distribution and grain size of the order of $\sim 2.28 \mu \mathrm{m}$. Detailed dielectric studies of the

$\mathrm{Pb}_{0.95}\left(\mathrm{La}_{1-\mathrm{z}} \mathrm{Bi}_{\mathrm{z}}\right)_{0.05}\left[\left(\mathrm{Zr}_{0.6} \mathrm{Ti}_{0.4}\right)_{0.95}\left(\mathrm{Mn}_{1 / 3} \mathrm{Sb}_{2 / 3}\right)_{0.05}\right] \mathrm{O}_{3}$ samples as a function of the temperature (from $25^{\circ} \mathrm{C}$ to $450^{\circ} \mathrm{C}$ ) at frequency $1 \mathrm{kHz}$ suggest that the compounds undergo a diffuse phase transition. The transition temperature shifts increase with increasing the Bi ratio. Diffusivity $(\gamma)$ study of phase transition of these compounds provided its value from 1.59 to 1.78 indicating the degree of the disordering in the system.
\end{abstract}

Keywords: PLZT Ceramics; Grain Size; Dielectric Properties; Diffusivity $(\gamma)$

\section{Introduction}

Since its discovery, the lead zirconate titanate (PZT) ceramic system has been widely used in transducer design due to its notable electromechanical features [1-3]. One of the main characteristics of the phase diagram of this perovskite compound is the existence of a Morphotropic Phase Boundary (MPB), approximately at $\mathrm{Zr} / \mathrm{Ti} \sim 53 / 47$ wish divides the rombohedral Zr-rich from tetragonal Tirich one. Samples with $\mathrm{Zr} / \mathrm{Ti}$ ratio near the MPB show the highest dielectric and piezoelectric responses [4].

On the other hand, PZT ceramics have been extensively modified (doped) with small amount of different additives that make them more attractive for any specific application. Such kinds of modification are classified as "soft" or "hard" by differentiating cases where the dopantion has, respectively, higher or lower valence than the targetion on the $\mathrm{ABO}_{3}$ perovskite cell [5]. Addition of donor dopants like La enhanced the electro optical and mechanical proprieties of ceramics [6,7]. In this formula $\mathrm{La}^{+3}$ ions goes to the A-site and vacancies are created on the B-site to maintain change balance. The influence of soft doping (trivalent $\mathrm{Bi}$ [8-13]) and hard doping (acceptors $\mathrm{Mn}$ and $\mathrm{Sb}$ [14-16]) in PLZT have been reported to have high electromechanical properties. However, the

"Corresponding author. relationship between morphological and electrical properties with reference to these combinatorial ceramic compositions with hard (acceptor $\mathrm{Mn}$ and $\mathrm{Sb} \mathrm{B}$-site) and soft (trivalent Bi A-site) doping in PLZT has not been addressed.

The aim of the present work is to study the morphological and dielectric properties of the

$\mathrm{Pb}_{0.95}\left(\mathrm{La}_{1-\mathrm{z}} \mathrm{Bi}_{\mathrm{z}}\right)_{0.05}\left[\left(\mathrm{Zr}_{0.6} \mathrm{Ti}_{0.4}\right)_{0.95}\left(\mathrm{Mn}_{1 / 3} \mathrm{Sb}_{2 / 3}\right)_{0.05}\right] \mathrm{O}_{3}$ ceramics. By using X-ray, SEM and the observed dielectric behavior and the temperature value will be interpreted in terms of a Ferroelectric-Paraelectric (FE-PE) phase transition.

\section{Experimental Procedure}

The ceramic samples were prepared by solid state reaction. High purity raw materials $\left(\mathrm{Pb}_{3} \mathrm{O}_{4}, \mathrm{ZrO}_{2}, \mathrm{TiO}_{2}, \mathrm{La}_{2} \mathrm{O}_{3}\right.$, $\mathrm{Bi}_{2} \mathrm{O}_{3}, \mathrm{MnO}_{2}$ and $\mathrm{Sb}_{2} \mathrm{O}_{3}$ ) were stoichiometrically weighed according to the composition

$\mathrm{Pb}_{0.95}\left(\mathrm{La}_{1-\mathrm{z}} \mathrm{Bi}_{\mathrm{z}}\right)_{0.05}\left[\left(\mathrm{Zr}_{0.6} \mathrm{Ti}_{0.4}\right)_{0.95}\left(\mathrm{Mn}_{1 / 3} \mathrm{Sb}_{2 / 3}\right)_{0.05}\right] \mathrm{O}_{3}$ via the chemical route for $\mathrm{z}=0.0,0.2,0.4$ and 0.6 . From now on, we shall refer to this compound as PLBZMST or 100/0, $80 / 20,60 / 40$ and 40/60 according to the $\mathrm{La}$ and $\mathrm{Bi}$ ratio. The batch powders were dispersed in acetone and mixed by a magnetic stirrer during two hours. The obtained paste is being dried at $80^{\circ} \mathrm{C}$, and then crushed in a mortar 
out of a glass during 4 hours. Powders were calcined at $900^{\circ} \mathrm{C}$ for 120 minutes with a heating rate of $2^{\circ} \mathrm{C} / \mathrm{min}$. calcined powders were crushed in a similar manner to the first crushing but with 6 hours, for better agglomerate size reduction. A 5\% polyvinyl alcohol (PVA) water solution was used as binder to increase the plasticity of the powders. The weight ratio between the PVA solution and the powders was 1:20. Powder and PVA solutions were mixed in a mortar and then uniaxially pressed into pellets with a pressure of $2000 \mathrm{~kg} / \mathrm{cm}^{3}$ in a cylindrical stainless steel dies using a hydraulic press. The size of those pellets was $13 \mathrm{~mm}$ in diameter; while the thickness is $1 \mathrm{~mm}$. Pellets were packed into covered alumina crucibles. The inner space of the crucibles was filled up with the powders of $\mathrm{PbZrO}_{3}$, in order to prevent intensive evaporation of the lead during the sintering. A typical sintering schedule consisted of heating rate of $2^{\circ} \mathrm{C} / \mathrm{min}$ to $1100^{\circ} \mathrm{C}$, $1150^{\circ} \mathrm{C}, 1180^{\circ} \mathrm{C}$ and $1200^{\circ} \mathrm{C}$, for 120 minutes and natural cooling in the furnace.

Powder X-ray diffraction was recorded by X-ray powder (Philips) diffractometer using $\mathrm{CuK} \alpha$ radiation $(\lambda=$ $1.5406 \AA)$ in a wide range of Bragg angles $\left(20^{\circ} \leq 2 \theta \leq\right.$ $60^{\circ}$ at a scanning rate of $2 \% \mathrm{~min}$. Densities of sintered pieces were calculated from the sample dimensions and weights. Microstructural features such as a grain size and pores were characterized by means of scanning electron microscopy (SEM). Sintered pellets were electrified by silver paste, and fired at $750^{\circ} \mathrm{C}$ for forty five minutes, before using for any electrical measurements. The dielectric permittivity and loss tangent of the samples were measured as a function of frequency at different temperature (room temperature to $500^{\circ} \mathrm{C}$ ) using LCR meter (Good Will Instrument Co., LTD).

\section{Results and Discussion}

X-ray diffraction patterns of PLBZMST (100/0, 80/20, $60 / 40$; and $40 / 60$ ) ceramics sintered at $1180^{\circ} \mathrm{C}$ are shown in "Figure 1". The PZT phase could be identified from $\mathrm{X}$-ray peaks in a range of $2 \theta \sim 42^{\circ}-47^{\circ}$ [17], wish cor responded to $(200)_{\mathrm{T}}-(002)_{\mathrm{T}}$ peaks of tetragonal $(\mathrm{T})$ structure. The associated changes in lattice parameter and degree of tetragonality (c/a) were calculated and listed in Table 1.

The calculated tetragonality of all the samples indicates that the addition of $\mathrm{Bi}$ to PLZMST does not cause mush variation in tetragonality, except that a pyrochlore peak is observed near the perovskite (110) for all the com-

Table 1. Lattice and dielectric parameters of PLBZMST samples.

\begin{tabular}{ccccc}
\hline $\begin{array}{c}\text { Lattice } \\
\text { parameters } \\
\text { in }(\AA)\end{array}$ & 0 & 2 & 4 & 6 \\
\cline { 2 - 5 } $\mathrm{a}=\mathrm{b}$ & 3.9615 & 3.9936 & 3.8928 & 3.9666 \\
$\mathrm{C}$ & 4.0725 & 4.1937 & 4.068 & 4.0619 \\
$\mathrm{c} / \mathrm{a}$ & 0.9727 & 0.9522 & 0.9659 & 0.9765 \\
$\mathrm{~V}\left(\AA^{3}\right)$ & 63.91 & 66.88 & 61.64 & 63.91 \\
\hline & & Physical parameters & \\
\hline$\varepsilon_{\mathrm{m}}$ & 13059.73 & 13275.19 & 21728.37 & 28272.79 \\
$\mathrm{~T}_{\mathrm{C}}\left({ }^{\circ} \mathrm{C}\right)$ & 350 & 360 & 360 & 410 \\
$\Delta \mathrm{T}_{\mathrm{m}}\left({ }^{\circ} \mathrm{C}\right)$ & 28 & 26 & 19 & 42 \\
$\gamma$ & 1.59 & 1.63 & 1.78 & 1.73 \\
\hline
\end{tabular}

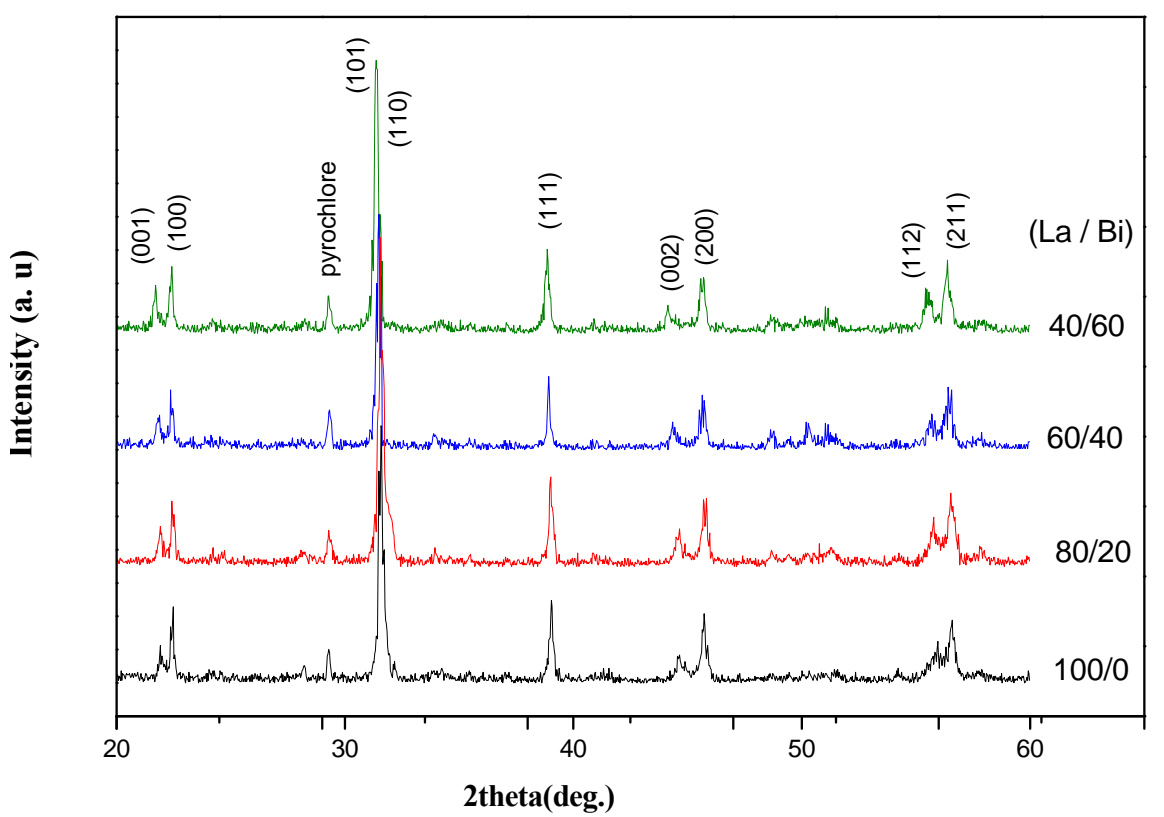

Figure 1. XRD patterns of PLBZMST sintered at $1180^{\circ} \mathrm{C}$. 
positions. The relative amount of the pyrochlore phase to the perovskite phase was esteemed using the following peak area ration equation [18].

$$
\text { pyrochlore } \%=\frac{\mathrm{A}_{\text {pyro. }}}{\mathrm{A}_{\text {pyro. }}+\mathrm{A}(100)} \times 100
$$

where $\mathrm{A}_{\text {pyro. }}$ and $\mathrm{A}(110)$ are the area under the pyrochlore peak and the (110) perovskite phase. The pyrochlore value is increased from $3 \%$ to $6 \%$ with increasing Bi doping, which is small and agreement with the value reported in doped PZT [19]. Hence, this composition can also be considered as a single phase wish confirms the homogeneous diffusivity of $\mathrm{Bi}^{3+}$ in PLZMST perovskite. The donors ions $\mathrm{Bi}^{3+}$ partially substitute $\mathrm{Pb}^{2+}$ at $\mathrm{A}$-site and acceptors $\mathrm{Mn}^{4+}$ and $\mathrm{Sb}^{3+}$ partially substitutes $\mathrm{Zr}^{4+}$ / $\mathrm{Ti}^{4+}$ at B-site due to the approximately close and similar ionic radii of respective cations at A-site and B-site in PLZT lattice.

Figure 2(a) shows the apparent density of undoped and Bi modified PLZMST ceramics at different sinteringtemperatures. This curve shows the similar variation trend with increasing sintering temperature. The density of the compositions sintered at $1180^{\circ} \mathrm{C}$ showed the maximum value of $7.56 \mathrm{mg} / \mathrm{cm}^{3}$ at ratio $\mathrm{La} / \mathrm{Bi}(60 / 40)$. The apparent densities (as a percentage of theoretical density) of the sintered pellets are shown in Figure 2(b). This figure shows that the composition doped with $4 \%$ of Bi has highest density values at each temperature sintering.

SEM micrographs of the pellet prepared from PLBZMST powder and sintered at $1180^{\circ} \mathrm{C}$ are shown in Figure 3. The sintered pellets have been found to have a grain size of the order of $\sim 2.28 \mu \mathrm{m}$ and uniform grain distribution, which is in accordance with the high density value as can be seen from Figures 2(a) and (b). The average grain size was determined directly from the SEM micrographs by using the classical linear interception method.

Permittivity and $\mathrm{AC}$ conductivity were analysed in the ferro and paraelectric phase. Figure 4(a) shows the variation of the dielectric constant $\left(\varepsilon_{\mathrm{r}}\right)$ as a function of temperature at frequency of $1 \mathrm{kHz}$. It is observed that $\varepsilon_{\mathrm{r}}$ increases with the increase of temperature up to the onset of phase transition. A significant improvement in values of $\varepsilon_{\mathrm{r}}$ has been observed with the increase of sintering temperatures. The value of dielectric constant $\left(\varepsilon_{\max }=21728.37\right)$ of the sample doped with $\mathrm{Bi}(60 / 40)$ at a transition temperature $\left(\mathrm{T}_{\mathrm{c}}=360^{\circ} \mathrm{C}\right)$ is a high as 2 times that of the other samples. On the other hand, while at room temperature; permittivity increased with dopants concentration mainly because of the lower values of porosity. This fact can be explained by using the Bruggeman model for inhomogeneous media [20].

Figure 4(b) shows the variety of dielectric loss $(\tan \delta)$ as a function of temperature at $1 \mathrm{kHz}$; for all the com-

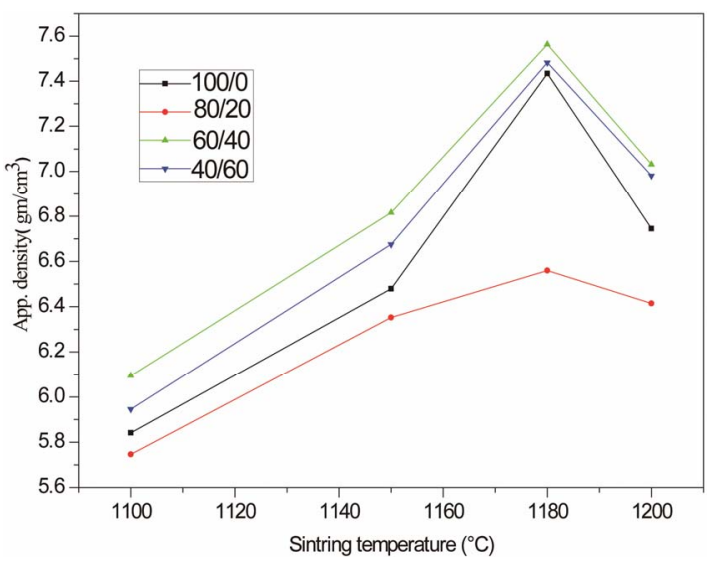

(a)

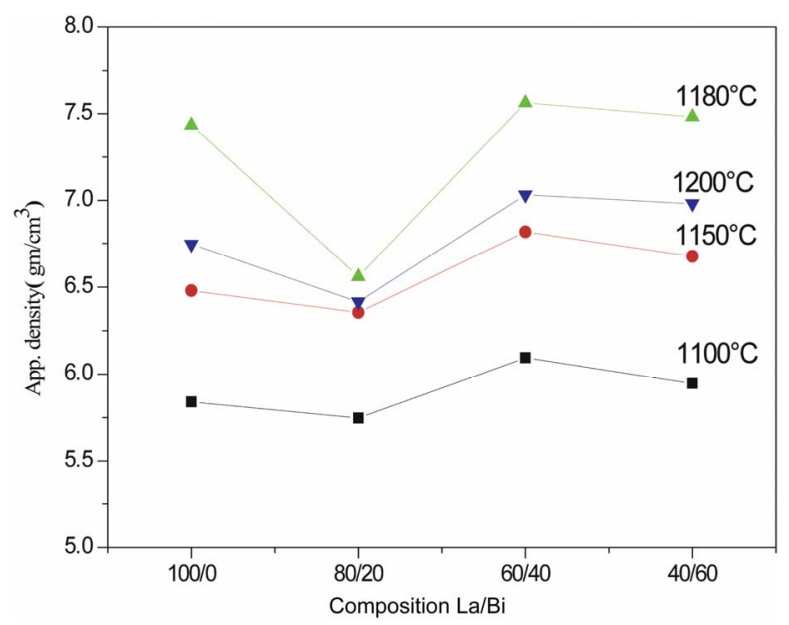

(b)

Figure 2. (a) Variation of apparent density of PLBZMST with sintered temperature; (b) Variation of apparent density of sintered PLBZMST samples with Bi addition.

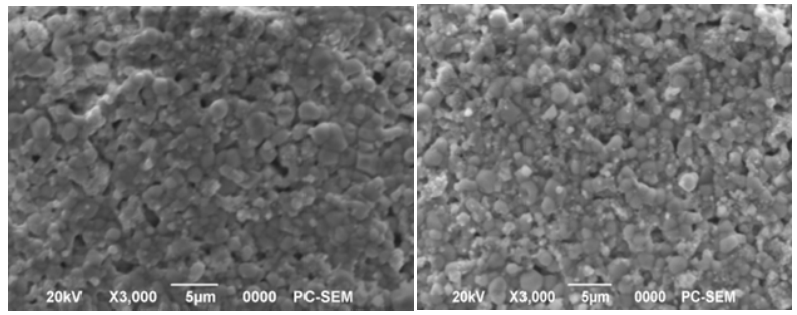

(a)

(b)

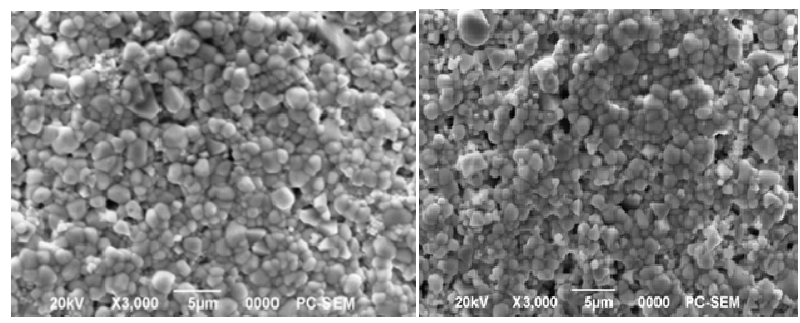

(c)

(d)

Figure 3. SEM micrographs of PLBZMST pellets (a) 100/0; (b) $80 / 20$; (c) $60 / 40 ;$ (d) $40 / 60$ sintered at $1180^{\circ} \mathrm{C}$. 


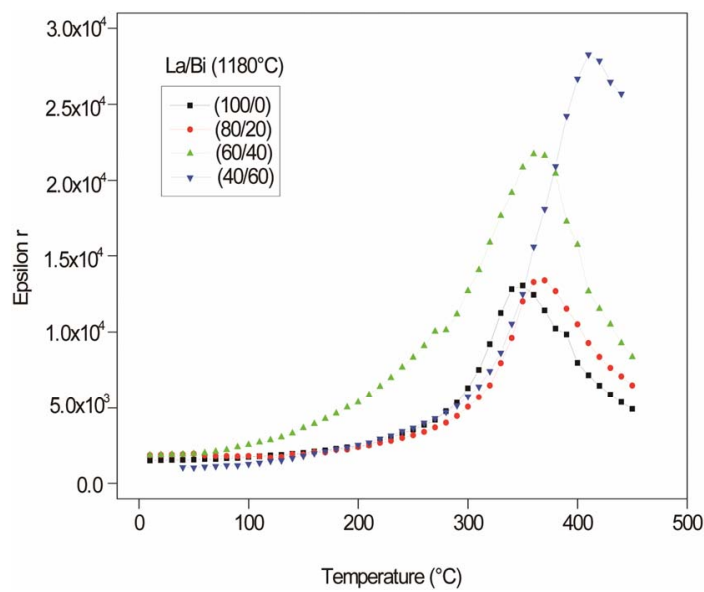

(a)

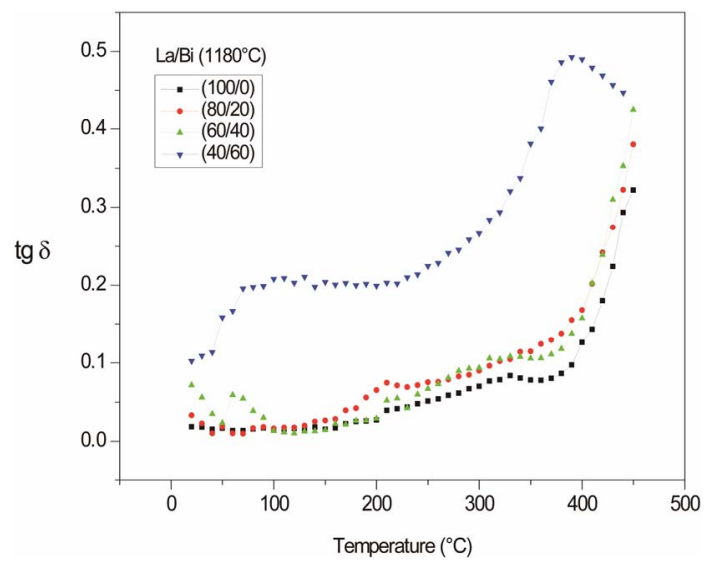

(b)

Figure 4. Variation of (a) Dielectric constant and (b) dielectric loss respectively with temperature at $1 \mathrm{kHz}$ for all samples sintered at $1180^{\circ} \mathrm{C}$.

positions, as temperature increase, loss tangent is almost constant up to $300^{\circ} \mathrm{C}$, but then it starts increasing with temperature. This increase in $(\tan \delta)$ may be due to an increase in the electrical conduction of the residual current and absorption current [21].

It is known that the dielectric constant $\varepsilon$ of a normal ferroelectric, above the curie temperature follows the Curie-Weiss Law [22] described by:

$$
\frac{1}{\varepsilon}=\frac{\mathrm{T}-\mathrm{T}_{0}}{\mathrm{C}} \quad\left(\mathrm{T}>\mathrm{T}_{\mathrm{c}}\right)
$$

where $\mathrm{T}_{0}$ is the Curie-Weiss temperature and $\mathrm{C}$ is the Curie-Weiss constant. Figure 5(a) shows the plot of temperature versus inverse dielectric constant (at $1 \mathrm{kHz}$ ) fitted to the Curie-Weiss law for PLZMST ceramics.

$$
\Delta \mathrm{T}_{\mathrm{m}}=\mathrm{T}_{\mathrm{cw}}-\mathrm{T}_{\mathrm{c}}
$$

The parameter $\Delta \mathrm{T}_{\mathrm{m}}$, to illustrate the degree of deviation from the Curie-Weiss law, was defined as where Tcw denotes the temperature from which the permittivity starts to deviate from the Curie-Weiss law, and Tm repre-

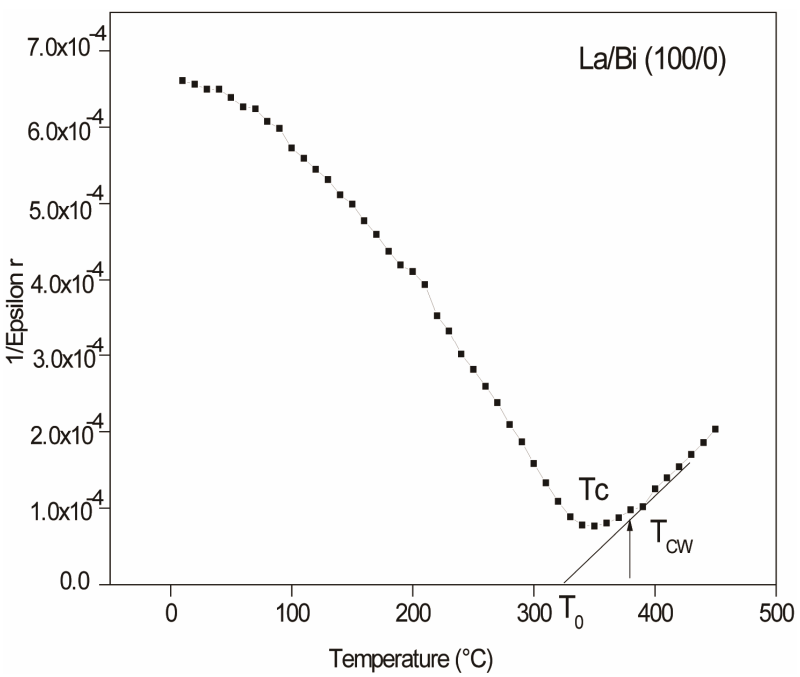

(a)

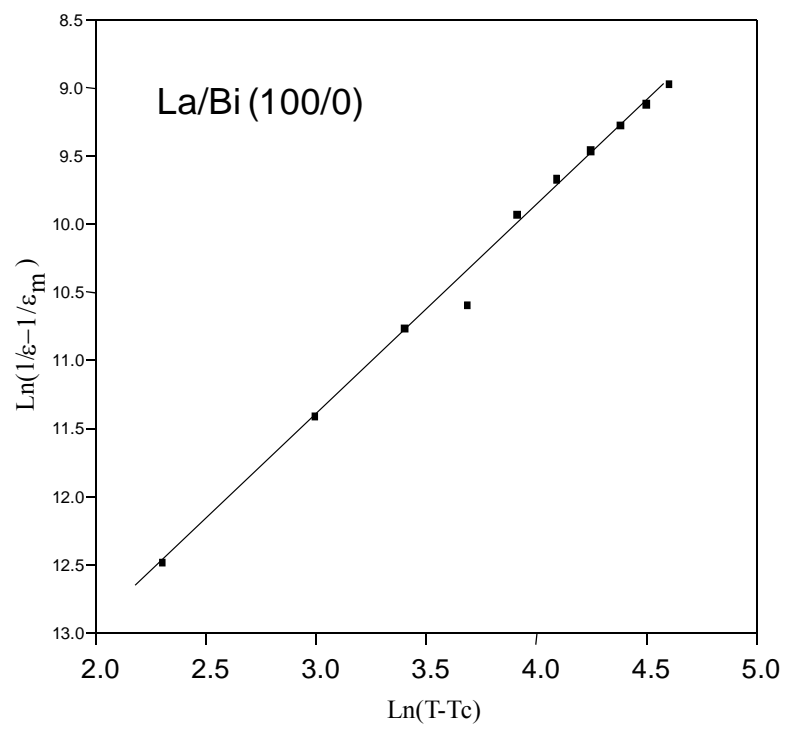

(b)

Figure 5. (a) The inverse $\varepsilon$ as a function of temperature at 1 $\mathrm{kHz}$ for PLBZMST; (b) $\ln \left(1 / \varepsilon-1 / \varepsilon_{\mathrm{m}}\right)$ vs. $\ln \left(\mathrm{T}-\mathrm{T}_{\mathrm{c}}\right)$ of PLZMST at $1 \mathrm{kHz}$.

sents the temperature of the dielectric constant maximum. At $1 \mathrm{kHz}$, it can be seen from Table 1 that the $\Delta \mathrm{T}_{\mathrm{m}}$ decreases slightly with increased $\mathrm{Bi}$ addition.

The dielectrics characteristics of relaxor ferroelectrics are known to deviate from the typical Curie-Weiss behavior and can be described by a modified Curie-Weiss relation-ship [23].

$$
\frac{1}{\varepsilon}-\frac{1}{\varepsilon_{\mathrm{m}}}=\frac{\left(\mathrm{T}-\mathrm{T}_{\mathrm{m}}\right)^{\gamma}}{\mathrm{C}} \quad 1 \leq \gamma \leq 2
$$

where $\gamma$ and $\mathrm{C}$ are assumed to be constant. The parameter $\gamma$ give information on the character of the phase transition: For $\gamma=1$, a normal Curie-Weiss law is obtained, $\gamma=$ 2 describe a complete diffuse phase transition [24]. Fig- 
ure 5(b) shows the plot of $\ln \left((1 / \varepsilon)-\left(1 / \varepsilon_{\mathrm{m}}\right)\right)$ versus $\ln (\mathrm{T}-$ $\left.\mathrm{T}_{\mathrm{m}}\right)$ at $1 \mathrm{kHz}$ of PLZMST sample. Linear relationships were observed. The slopes of the fitting curve were used to determine the parameter $\gamma$. The values of $\gamma$ are listed in Table 1. It can be seen the increase in value of $\gamma$ with $\mathrm{Bi}_{2} \mathrm{O}_{3}$ content (Table 1) indicates an increase in diffusivity.

\section{Conclusion}

The novel PLBZMST ceramics have been prepared by conventional solid-state reaction route. All the compounds are crystallized in pure perovskite phase with the predominant tetragonal phase. Grain size was obtained in the order of $\sim 2.28 \mu \mathrm{m}$ and uniform grain distribution wish is in accordance with the density. The increase in core temperature and dielectric constant can be attributed to the emerging lead vacancies creation by donor cations (Bi), and acceptor to reduce the oxygen vacancies mobility to balance charge in the modified PLZMST. The diffusivity $(\gamma)$ study of phase transition of these compounds gives the values from 1.59 to 1.78 indicating the degree of the disordering in the system.

\section{REFERENCES}

[1] B. Jaffe, W. R. Cook Jr. and H. Jaffe, "Piezoelectric Ceramics," Academic Press, New York, 1971.

[2] G. H. Haertling, "Ferroelectric Ceramics: History and Technology," Journal of the American Ceramic Society, Vol. 82, No. 4, 1999, pp. 797-818. doi:10.1111/j.1151-2916.1999.tb01840.x

[3] B. Jaffe, R. S. Roth and S. Marzullo, "Piezoelectric PropErties of Lead Zirconate-Lead Titanate Solid-Solution Ceramics," Journal of Applied Physics, Vol. 25, No. 6, 1954, pp. 809-810. doi:10.1063/1.1721741

[4] F. Agullo-Lopez, J. M. Carbrera and F. Agullo-Rueda, "Electrooptics Phenomena, Materials and Applications," Academic Press INC, San Diego, 1994, pp. 146-149.

[5] R. Rai, S. Sharma and R. N. P. Choudhary, "Effect of Al Doping on Structural and Dielectric Properties of PLZT Cramics," Journal of Materials Science, Vol. 41, No. 13, 2006, pp. 4259-4265. doi:10.1007/s10853-005-5455-1

[6] H. Tamura, T. Knolle, Y. Sakable and K. Wakino, "Improved High-Q Dielectric Resonator with Complex Perovskite Structure," Journal of the American Ceramic Society, Vol. 67, No. 4, 1984, pp. C59-C61.

[7] K. Wakino, K. Minal and H. Tamura, "Microwave Characteristics of $(\mathrm{Zr}, \mathrm{Sn}) \mathrm{TiO}_{4}$ and $\mathrm{BaO}-\mathrm{PbO}-\mathrm{Nd}_{2} \mathrm{O}_{3}-\mathrm{TiO}_{2}$ Dielectric Resonators," Journal of the American Ceramic Society, Vol. 67, No. 4, 1984, pp. 278-281. doi:10.1111/j.1151-2916.1984.tb18847.x

[8] S. Dutta, R. N. P. Choudhary and P. K. Sinha, "Ferroelectric Phase Transition in Bi-Doped PLZT Ceramics," Materials Science and Engineering: B, Vol. 98, No. 1, 2003, pp. 74-80. doi:10.1016/S0921-5107(02)00612-8
[9] R. N. P. Choudhary, "Phase Transition in Bimodified PLZT Ferroelectrics," Materials Letters, Vol. 54, No. 2, 2002, pp. 175-180. doi:10.1016/S0167-577X(01)00559-6

[10] P. Goel, K. L. Yadav and A. R. James, "Double Doping Effect on the Structural and Dielectric Properties of PZT Ceramics," Journal of Physics: Applied Physics, Vol. 37, No. 22, 2004, pp. 3174-3179. doi: $10.1088 / 0022-3727 / 37 / 22 / 019$

[11] S. Dutta, R. N. P. Choudhary and P. K. Sinha, "Ferroelectric Phase Transition in Sol-Gel Derived Bi-Doped PLZT Ceramics," Journal of Materials Science, Vol. 39, No. 9, 2004, pp. 3129-3135. doi:10.1023/B:JMSC.0000025842.46451.64

[12] P. Goel and K. L. Yadav, "Substitution Site Effect on Structural and Dielectric Properties of La-Bi Modified PZT," Journal of Materials Science, Vol. 42, No. 11, 2007, pp. 3928-3935. doi:10.1007/s10853-006-0416-X

[13] R. Rai, S. Sharma and R. N. P. Choudhary, "Structural and Dielectric Properties of Bi Modified PLZT Ceramics," Solid State Communications, Vol. 133, No. 10, 2005, pp. 635-639. doi:10.1016/j.ssc.2005.01.005

[14] Y. K. Gao, K. Uchino and D. Viehland, "Rare Earth Metal Doping Effects on the Piezoelectric and Polarization Properties of $\mathrm{Pb}(\mathrm{Zr}, \mathrm{Ti}) \mathrm{O}_{3}-\mathrm{Pb}(\mathrm{Sb}, \mathrm{Mn}) \mathrm{O}_{3}$ Ceramics," Journal of Applied Physics, Vol. 92, No. 4, 2002, pp. 20942099. doi:10.1063/1.1490617

[15] Z. G. Zhu, Z. J. Xu, W. Z. Zhang and Q. R. Yin, "Effect of PMS Modification on Dielectric and Piezoelectric Properties in XPMS- $(1-\mathrm{x})$ PZT," Journal of Physics: Applied Physics, Vol. 38, No. 9, 2005, pp. 1464-1469. doi:10.1088/0022-3727/38/9/021

[16] R. Rai, S. Mishra and N. K. Singh, "Effect of Fe and Mn Doping at B-Site of PLZT Ceramics on Dielectric Properties," Journal of Alloys Compounds, Vol. 487, No. 40180, 2009, pp. 494-498. doi:10.1016/j.jallcom.2009.07.161

[17] K. Kakegawa, J. Mohri, T. Takahashi, H. Yammamura and K. Shirasaki (Solid State Communication), "A Compositional Fluctuation and Properties of $\mathrm{Pb}(\mathrm{Zr}, \mathrm{Ti}) \mathrm{O}_{3}$," Solid State Communications, Vol. 24, No. 11, 1977, pp. 769-772. doi:10.1016/0038-1098(77)91186-3

[18] A. Garg and D. C. Agarwal, "Effect of Rare Earth (Er, Gd, $\mathrm{Eu}, \mathrm{Nd}$ and $\mathrm{La}$ ) and Bismuth Additives on the Mechanical and Piezoelectric Properties of Lead Zirconate Titanate Ceramics," Materials Science and Engineering: B, Vol. 86, No. 2, 2001, pp. 134-143. doi:10.1016/S0921-5107(01)00655-9

[19] S. R. Shanningrahi, F. E. H. Tay, K. Yao and R. N. P. Choudhary, Effect of Rare Earth (La, Nd, Sm, Eu, Gd, Dy, $\mathrm{Er}$ and $\mathrm{Yb}$ ) Ion Substitutions on the Microstructural and Electrical Properties of Sol-Gel Grown PZT Ceramics," Journal of the European Ceramic Society, Vol. 24, No. 1, 2004, pp. 163-170. doi:10.1016/S0955-2219(03)00316-9

[20] A. Pelaiz-Barranco, "Ferroelectric Properties and Conduction Mechanisms in the Modified PZT Ceramic System," Ph.D. Thesis, University of Havana, Havana, 2001.

[21] B. Tareev, "Physics of Dielectric Materials," Mir Publisher, Moscow, 1979, p. 157.

[22] M. E. Lines and A. M. Glass, "Principles and Application 
of Ferroelectric and Related Materials," Clarendon Press, Oxford, 1977.

[23] V. Koval, C. Alemany, J. Briančin and H. Bruncková, "Dielectric Properties and Phase Transition Behavior of xPMN-(1 - x)PZT Ceramic Systems," Journal of Elec- troceramics, Vol. 10, No. 1, 2003, pp. 19-29.

[24] G. A. Smolenskii, "X-Ray Scattering and the Phase Transition of $\mathrm{KMnF}_{3}$ at $184 \mathrm{~K}$," Journal of the Physical Society of Japan, Vol. 28, No. 2, 1970, pp. 26-37. doi:10.1023/A:1024023823871 